\title{
A topologia ESTRUTURAL de LACAN
}

\author{
Vitor Hugo Couto Triska* \\ Marta Regina de Leão D'Agord**
}

\section{Resumo}

Neste trabalho, busca-se construir uma apresentação do uso da topologia por Lacan, questionando a sua fundamentação, função e pertinência à psicanálise. Para tanto, aborda-se a noção de modelo, um tipo de abstração central no contexto do estruturalismo, assim como a oposiçâo entre homologia e analogia a partir da qual será elucidada uma crucial contribuição de Lacan à teoria psicanalítica, isto é, a proposta de um novo método de pesquisa - a topologia estrutural, cujos aspectos metodológico e ontológico serão discutidos.

Palavras-chave: topologia; estrutura; Lacan; pesquisa.

\section{Abstract}

\section{The STRUCTURAL TOPOLOGY OF LACAN}

This paper seeks to build a presentation of Lacan's use of topology, questioning its reasoning, function and relevance to psychoanalysis. To this purpose, it explores the notion of model, an important kind of abstraction in the structuralism context, as well as the opposition between homology and analogy, from which a crucial contribution from Lacan to the psychoanalytic theory will be elucidated, meaning the proposal of a new research method - the structural topology, whose ontological and methodological aspects will be discussed.

Keywords: topology; structure; Lacan; research.

* Doutorando no Programa de Pós-Graduação em Psicologia Social e Institucional do Instituto de Psicologia da Universidade Federal do Rio Grande do Sul. Porto Alegre, Rio Grande do Sul, Brasil. Email: vitortriska@yahoo.com.br.

** Departamento de Psicanálise e Psicopatologia / Programa de Pós-Graduação em Psicologia Social do Instituto de Psicologia da Universidade Federal do Rio Grande do Sul. Porto Alegre, Rio Grande do Sul, Brasil. Email: mdagord@terra.com.br. 


\section{Resumen}

LA TOPOLOGía ESTRUCTURAL DE LACAN

En este trabajo, tratamos de construir una presentación del uso de la topología por Lacan, cuestionando su razón de ser, su función y su importancia en psicoanálisis. Por lo tanto, se enfoca la noción de modelo, una especie de abstracción de base en el contexto del estructuralismo, asi como la oposición entre homología y analogía de la cual se aclarará la contribución crucial de la teoría psicoanalítica de Lacan, es decir, la propuesta de un nuevo método de investigación - la topología estructural, cuyos aspectos ontológico y metodológicos se discutirá.

Palabras clave: topología; estructura; Lacan; investigación.

\section{Introduçáo}

Em $A$ angústia (1962-1963/2005, p. 97), Lacan cita uma passagem de Freud, situada na conferência XXXII das "Novas conferências introdutórias sobre psicanálise" (1933 [1932]/1996b, p. 85): "É, contudo, verdadeiramente uma questão de concepções - isto é, de introduzir as ideias abstratas corretas, cuja aplicação ao material bruto da observação nele produzirá ordem e clareza”. Logo após essa citação, Lacan complementa: "Com efeito, esse projeto é justamente aquele em que nos empenhamos aqui há alguns anos" (1962-1863/2005, p. 98). É interessante como uma explícita influência do ensino lacaniano, a saber, a utilização do modelo - conforme tomado no contexto do estruturalismo e referenciado a Lévi-Strauss -, coincide com a teorização julgada necessária por Freud, isto é, abstrações que mesmo ausentes do conjunto de elementos observáveis lhe conferem ordem e inteligibilidade. Surge desde já uma primeira proposta: a metapsicologia freudiana trata de apreender, ou melhor, propor uma lógica subjacente ao "material bruto da observação". Se uma lógica inconsciente subjaz às associaçóes, ideias súbitas (einfall), formaçóes do inconsciente e todo "material bruto" que seja considerado numa psicanálise, conclui-se que tal lógica, as "ideias abstratas", é necessariamente imaterial e espacial. Nas palavras do próprio Freud (1926/1996a, p. 189), "Deixaremos inteiramente de lado a linha material de abordagem, mas não a espacial'.

A partir daí, nosso problema central apresenta-se: as abstrações que compõem a teoria psicanalítica mantêm que tipo de relaçấo com o seu objeto, isto é, o psíquico? Em psicanálise, a teoria e seus modelos são representaçôes intuitivas do objeto que aborda? Seriam, de outra forma, esses modelos teóricos o próprio objeto? São questóes centrais deste artigo e que serão trabalhadas a partir da im-

Psic. Clin., Rio de Janeiro, vol. 25, N.I, P. I45 - I6I, 2013 
plementaçáo lacaniana da topologia na psicanálise, característica imprescindível do retorno a Freud.

\section{O modelo e a estrutura no estruturalismo}

Uma significativa afirmação de Lacan (1960/1998b, p. 654) torna importante que nos detenhamos sobre uso do modelo teórico e da noção de estrutura no contexto do estruturalismo: "fazemos do termo estrutura um emprego que cremos poder pautar no de Claude Lévi-Strauss”. Esclareçamos, então, a noção de modelo no estruturalismo. Eduardo Prado Coelho assim o apresenta:

o processo de conhecimento consistiria em abstrair do real a sua essência; o produto dessa abstraçáo seria o modelo; e, nesse caso, o modelo corresponderia apenas a uma representaçáo aproximada do real, construída com o fim de melhor manipular esse real em função de necessidades práticas (Coelho, 1967, p. 27).

Embora Coelho proponha o modelo como "representação aproximada" do real, mantendo assim a prevalência da matéria observável, o modelo de Lévi-Strauss parece ir além de ser apenas uma representação, pois confere à abstração, e não à matéria, a presença da estrutura:

As relaçóes sociais são a matéria-prima empregada para a construção de modelos que tornam manifesta a própria estrutura social, que jamais pode, portanto, ser reduzida ao conjunto das relaçôes sociais observáveis em cada sociedade (Lévi-Strauss, 1952/2008, p. 301; grifo do autor).

Explicitam-se, entâo, duas vias. Na primeira, dedutiva-explicativa, o modelo é apenas uma representação aproximada, criada para fins de inteligibilidade. $\mathrm{Na}$ segunda, indutiva, o modelo é, ele mesmo, o próprio meio de tornar manifestas as leis de interaçóes dos dados observáveis.

Apenas no segundo caso se pode afirmar que a estrutura está concebida como imaterial, como algo da ordem do próprio modelo, não do dado observável. Piaget, em $O$ estruturalismo, assim esclarece:

o característico de um estruturalismo metódico é procurar a explicação desse sistema em uma estrutura subjacente que permite, de certo modo,

Psic. Clin., Rio De Janeiro, vol. 25, N.I, P. I45 - I6I, 2013 
sua interpretação dedutiva e que se trata de reconstituir pela construção de modelos lógico-matemáticos: nesse caso, e isso é fundamental, a estrutura não faz parte do domínio dos "fatos" constatáveis e, em particular, permanece "inconsciente" aos membros individuais do grupo considerado (Piaget, 2003, p. 86).

Do acima exposto recortam-se dois pontos: (a) o modelo teórico torna manifesta a estrutura enquanto organização subjacente do conjunto de dados observáveis; (b) essa estrutura é uma abstração; logo, imaterial e ausente do conjunto de dados observáveis. Recolocam-se as perguntas que propusemos mais acima: o modelo é algum tipo de representaçáo da estrutura ou, de outra forma, modelo e estrutura são uma e mesma coisa? Que tipo de relação tem o modelo teórico com o seu objeto? Nosso interesse não será buscar as respostas no contexto do estruturalismo, mas reencontrar essas perguntas no campo da psicanálise.

Assim como Piaget (2003, p. 122), que afirma que "o estruturalismo é um método e não uma doutrina”, Umberto Eco, em A estrutura ausente (2007), reafirma o caráter de método do uso da noçáa de estrutura, mas, por sua vez, opondo-o a um possível aspecto ontológico, que o autor critica, pois que este propóe a estrutura como um sistema já dado, intrínseco ao objeto abordado e, portanto, "natural", ou ainda como um código originário, o Código dos códigos, que tudo determina e explica. Jacques Derrida, em "A estrutura, o signo e o jogo no discurso das ciências humanas" (1967), propóe uma leitura crítica da noção de estrutura em Lévi-Strauss baseada na análise que o antropólogo realizou sobre os mitos, que discorda da crítica de Eco no que diz respeito a um suposto aspecto ontológico em Lévi-Strauss e Lacan. Segundo Eco, esses autores se apoiam na existência de uma estrutura primordial, uma espécie de código último. Derrida, por sua vez, demonstra que em Lévi-Strauss, e nós diríamos que o mesmo serve para Lacan, a estrutura não é totalizante, carecendo, portanto, de um centro que a garanta como código último. Não poderemos tomar essa questáo com a devida complexidade aqui. A partir dela, porém, poderemos discutir o valor de método que possui a referência lacaniana à topologia, assim como a afirmaçáo de Nasio (1991, p. 114) que, numa nota de rodapé, sugere que a ferramenta topológica corresponde, para a psicanálise, ao "ser do psíquico, o estatuto ontológico do psiquismo".

Exposta essa problemática, passemos agora à incorporação, realizada por Lacan, da topologia à psicanálise, pela qual as questóes anteriormente colocadas poderão ser revistas no campo da teoria psicanalítica.

Psic. Clin., Rio de Janeiro, vol. 25, N.I, P. I45 - I6I, 2013 


\section{A topologia das superfícies em Lacan}

"Insisti, nesse sistema [o sistema $\Psi$, inconsciente], sobre sua característica extraplana, na sua característica de superfície sobre a qual Freud insiste com toda força, o tempo todo", afirma Lacan (1961-1962/2003b, p. 134), e logo na sequência cita Freud, uma passagem de "O ego e o id": "o eu é antes de tudo uma entidade corporal, não somente uma entidade toda em superfície, mas uma identidade correspondente à projeçáo de uma superfície". Aqui a leitura lacaniana de Freud acentua a existência de uma singularidade que possui características de superfície, caminho que é percorrido durante todo seminário $A$ identificação (Lacan, 1962-1963) através do estudo da topologia e do conceito de traço. O sujeito é apresentado como a estrutura de uma superfície topologicamente definida, determinada pelo corte, ou seja, a estrutura é uma superfície e o significante é o corte que a revela (Lacan, 1961-1962/2003b, p. 347). Como continuidade do movimento de aproximação à matemática e à lógica, em De um Outro ao outro (1968-1969/2008, p. 11), Lacan afirma: "A essência da teoria psicanalítica é um discurso sem palavras". Tal proposta teve sequência no seminário seguinte com a elaboração dos quatro discursos redutíveis a matemas, percurso que culminou no seminário de título De um discurso que não fosse semblante (Lacan, 1971/2009). Em "O aturdito" (Lacan, 1972/2003a), a busca pela redução a um discurso matemático-topológico cuja função não seja meramente explicativa aparece de maneira ainda mais manifesta na medida em que Lacan se apoia no discurso matemático, onde sentido e metáfora são rechaçados, uma vez que é o Real que é abordado. É o que Eidelsztein (1992, p. 19) chama de passagem da intuição imaginária à representação simbólica.

Limitaremos a abordagem da topologia de acordo com o que for necessário para compreender o uso dessa ferramenta em Lacan, utilizando, para tanto, uma exposição compreensiva dos fundamentos da topologia das superficies. Embora não se limite ao uso das superfícies, é através destas que o autor deu início a um uso mais aprofundado e sistemático da topologia. Nota-se, todavia, que ferramentas formais já anteriormente se faziam presentes em sua obra através de matemas, esquemas e modelos (não é o mesmo modelo do contexto estruturalista, veremos). O uso da topologia das superfícies permite uma releitura do valor de método que possui o emprego dessas ferramentas. No caso do Esquema R, por exemplo, em uma nota de rodapé incluída posteriormente no escrito "De uma questão preliminar a todo tratamento possível da psicose" - a nota é de 1966, o escrito de 1957-1958 -, Lacan ressignifica o esquema ao lhe atribuir o caráter de uma superfície topológica. Reler os esquemas e modelos do ponto de vista 
topológico permitirá, conforme veremos mais adiante, extrair consequências importantes da oposição entre homologia e analogia.

Segundo Sampaio (2002, p. 1), "superfícies são objetos geométricos bidimensionais que não existem no mundo real, mas apenas em nossa imaginação geométrica platônica”. Essa definição permite uma aproximação, no que diz respeito ao seu caráter abstrato, imaterial, entre a superfície topológica e a noção de estrutura. Em "O aturdito" (1972/2003a), Lacan cunha a expressão "topologia estrutural", sugerindo explicitamente que as superfícies topológicas sejam consideradas estruturas. Em "Observação sobre o relatório de Daniel Lagache" (1960/1998b, p. 655), há uma outra referência fundamental: "Ora, a estrutura não é a forma [...], e a questão é justamente abrir o pensamento para uma topologia, exigida pela simples estrutura”. Para a concepção de uma topologia estrutural, deve-se, portanto, conferir à superfície topológica o mesmo caráter de abstração da estrutura, conforme apreendida pelo modelo teórico do estruturalismo. Sigamos nossa exposição a fim de reunir mais elementos que fundamentem essa proposta.

Ao representar uma superfície topológica no espaço comum, tridimensional, euclidiano, o que pode ser feito construindo-a materialmente, realiza-se o que se chama de submersão ou mergulho. Uma vez mergulhada, devido a sua materialidade se a percebe intuitivamente, isto é, imaginariamente. Segundo Eidelsztein (2006, p. 19): "Nossa surpresa diante da topologia e a sensação de estranheza que nos produz estão motivadas pela incapacidade de nossa intuição espacial para captar as propriedades do espaço [...]". O mesmo autor, diante da pergunta "Por que a topologia?", afirma: "Porque é a única via da qual dispomos para aceder à estrutura real do espaço. A intuição não nos serve por muitíssimos motivos" (Eidelsztein, 2006, p. 22). A fita de Moebius, por exemplo, mergulhada em três dimensōes, parece possuir não uma, mas duas faces; é uma manobra da nossa intuição espacial comum. Se a mesma fita de Moebius, porém, adquire uma representação simbólica e bidimensional, que possibilite a elaboração mental correta de sua abstração, como desenhá-la achatada sobre um papel, suas verdadeiras propriedades topológicas náo serão confundidas com o seu aspecto imaginário, isto é, a imagem que fazemos dela quando materializada, mergulhada. É, repetimos, a passagem da intuição imaginária à representação simbólica.

A noção de estrutura é a mesma na linguística e na topologia? Podemos afirmar que, no contexto do ensino lacaniano, há uma equiparação. "A topologia não foi 'feita para nos guiar' na estrutura. Ela é a estrutura - como retroação da ordem de cadeia em que consiste a linguagem” (Lacan, 1972/2003a, p. 485). Essa ligaçáo é especialmente importante; afinal, num primeiro momento de seu

Psic. Clin., Rio De JANEIRo, vol. 25, N.I, P. I 45 - I6I, 2013 
ensino, Lacan apresenta a estrutura a partir da linguística, para depois o fazer a partir da topologia. Em "O seminário sobre 'A carta roubada” (1966/1998c) é demonstrado o funcionamento de retroação no qual a estrutura se revela. A cada lance novo de - ou + a cadeia é reestruturada desde seu início, ou melhor, sua estrutura se torna mais manifesta. Chega-se a um ponto onde, enfim - e é o que Lacan demonstra no subcapítulo Parêntese dos Parênteses -, pode-se apreender graficamente, no plano bidimensional, a estrutura à qual o acaso dos lances está submetido; apreensão que só se dá retroativamente, o que se conhece por après-coup.

Cada lance é diferença pura em relação ao outro, demonstrando o mesmo caráter do significante enquanto diferença radical a todos os outros. Um autor que realiza o particular esforço de aproximar a topologia da linguística, ou melhor, de explicitar a topologia do significante é Marc Darmon (1994):

O fato de se endereçar à linguística parece tanto mais justificado na medida em que Saussure demonstrou que a língua se suporta tão somente a partir de um jogo de puras diferenças e de lugares; de diferenças que não assumem seu valor senão a partir dos locais que ocupam. É então o próprio simbólico que introduz uma topologia (Darmon, 1994, p. 11).

\section{Seguimos com Darmon (1994):}

No plano topológico, ser-nos-ia entáo preciso conceber um espaço topológico munido de relaçốes de vizinhança, cujos pontos não seriam entáo separados, mas intimamente ligados uns aos outros. Eles teriam, por outro lado, a propriedade curiosa de serem diferentes de si mesmos (Darmon, 1994, p. 24).

O autor sustenta, portanto, as propriedades topológicas de uma cadeia significante, reconhecendo na mesma as características das superfícies. A distância entre dois pontos não existe, pois, uma vez que são vizinhos, são infinitamente próximos, apesar de qualquer deformação sobre a superfície.

É preciso então levar-se em conta a estrutura topológica muito paradoxal do significante. Efetivamente, cada significante está intimamente ligado a todos os outros, e ele próprio não é senão um puro corte. Ou seja, é preciso conceber uma conexidade sem substância, uma conexidade feita de puras diferenças (Darmon, 1994, p. 132).

Psic. Clin., Rio De Janeiro, vol. 25, N.I, P. I45 - I6I, 2013 
Para melhor conceber a sua bidimensionalidade, costuma-se sugerir que, sobre as superfícies, imaginemos seres fictícios, como formigas, que só se movem em contato com as mesmas, ou seja, "para frente", "para trás", "à direita" e "à esquerda"; ir "para cima" ou "para baixo" só seria possível num ambiente com três dimensōes (Sampaio, 2002, p. 2). Esse exercício verifica, tomando novamente como exemplo a fita de Moebius, que tal superfície, ao contrário do que possa parecer, possui apenas uma face. Apesar de aparentar ter duas faces, a fita de Moebius mantém suas características estruturais quando mergulhada. O cross-cap, por sua vez, necessita ser mergulhado num espaço de quatro dimensôes para não ter suas propriedades alteradas, daí a impossibilidade de construí-lo adequadamente. As superfícies topológicas, todavia, não são o objeto de papel, borracha ou tecido que podemos construir. Esses objetos que podemos tocar, que têm peso e medidas, não passam de um suporte material que representa e concede uma imagem à superfície e que, caso não estejamos cientes dos seus limites representativos, pode ser erroneamente tomado como a própria superfície. Assim, o espaço topológico, Real, compreende as propriedades dos objetos que independem dos nossos instrumentos de medida (comprimento, largura, ângulos, etc).

Se, para reconhecer as propriedades topológicas, é necessário o exercício de deixar de perceber apenas intuitivamente as superfícies, não há aí um princípio comum à escuta psicanalítica, ou seja, deixar de escutar o sentido mais comum e aparente da fala em busca das associaçóes ainda latentes e mais além da intenção consciente? Tomando a topologia como guia expositivo estaríamos nos servindo da intuição espacial euclidiana, o que corresponderia, no campo na clínica psicanalítica, a uma escuta orientada pelo Imaginário, prática criticada por Lacan (1976-1977): "Ele [o imaginário] é enganoso, mas é dele que se levanta isso que chamamos a consciência. A consciência está bem longe de ser o saber, uma vez que isto a que ela serve é muito precisamente à falsidade".

Há diferentes tipos de deformaçôes que alteram as superfícies em diferentes níveis, isto é, existem modificaçôes que atingem apenas a sua forma e modificaçôes que incidem sobre características estruturais. As primeiras podem ser chamadas de deformações legais, e são elas:

1. Esticar ou inchar a superfície ou partes dela.

2. Encolher a superfície ou partes dela.

3. Entortar a superfície ou partes dela.

4. Cortar a superfície segundo uma linha suave nela demarcada e, posteriormente, colar novamente, uma na outra, as bordas geradas por esse

Psic. Clin., Rio de Janeiro, vol. 25, N.I, P. I45 - I6I, 2013 
recorte, resgatando a superfície original com a linha demarcada. A este procedimento é dado o nome de recorte e colagem" (Sampaio, 2002, p. 2; grifo do autor).

O conjunto de características geométricas de uma superfície que não se alteram ao sofrer quaisquer das quatro deformações descritas caracteriza a topologia de uma superficie (Sampaio, 2002, p. 3). No contexto da topologia estrutural, a topologia de uma superfície será o mesmo que a sua estrutura, enquanto conjunto das suas propriedades invariantes às deformaçóes citadas. Apresenta-se outra comparação importante com a escuta psicanalítica: escutar os elementos discursivos que se repetem involuntariamente, que insistem apesar das formas e dos sentidos explícitos. As deformações de segundo tipo, as ilegais, que alteram a topologia (ou estrutura) de uma superfície, modificando suas invariantes, são:

(i) cortar a superfície, segundo uma curva nela demarcada, e não tornar a colar, um no outro, os bordos gerados pelo recorte;

(ii) realizar colagens de modo arbitrário fazendo com que dois ou mais pontos, originalmente separados, tornem-se um só ponto da superfície;

(iii) encolher a superfície, ou algumas de suas regióes, de modo que pontos originalmente separados se aglutinem num só ponto (Sampaio, 2002, p. $3)$.

Dentre as propriedades topológicas atribuídas às superfícies, para que se as compreenda em termos de estrutura e assim interessem à psicanálise, Carlos Ruiz (1994) destaca o fato de que sobre elas podemos traçar linhas, ou seja, fazer cortes que podem modificar sua topologia. É a proposta lacaniana do significante enquanto corte, como descontinuidade no contínuo da estrutura superficial. Entấo, é o corte, a primeira das modificaçôes ilegais conforme definidas por Sampaio, que interessa ao trabalho psicanalítico, sendo a superfície o suporte da operaçáo de corte. Segundo Lacan (1972/2003a, p. 479), a topologia "deve dar conta de que haja cortes do discurso tais que modifiquem a estrutura que ele acolhe originalmente". Segundo Ruiz (1994, p. 90), os elementos fundamentais são: "a superfície, uma linha sobre a superfície, que às vezes chamamos de marca, a operação de corte, a superfície resultante do corte, que não é de partida, e na qual a marca foi reposicionada por uma linha, que em algum sentido a duplica”. As características topológicas de uma superfície se explicitam eficazmente não pela sua aparência, mas pelas relaçóes de proximidade que se mantêm através das deformaçóes legais, pelas linhas possíveis e ainda pelos cortes que, de acordo com 
a especificidade de cada superfície, revelam suas reais propriedades. Um corte ao longo da fita de Moebius tem uma consequência bastante diferente do que ao longo de uma fita comum, de duas faces, por exemplo.

Nasio, em Os olhos de Laura (1991), faz uma interessante proposta, também propondo evidentes correspondências com a clínica:

Em que a prática com os objetos topológicos pode transformar, nos psicanalistas que a ela se dedicam, as condiçóes de seu imaginário? E em que medida modificando esse imaginário, adaptado às exigências da topologia, pode levar o psicanalista a escutar diferentemente seus analisantes e a sua própria experiência? (Nasio, 1991, p. 115).

Aqui, Nasio é preciso: a escuta psicanalítica não se orienta pelo Imaginário, isto é, pelo sentido, pelo inteligível; afinal, é evidente que a escuta do significante e a leitura da letra são operaçóes que destacam aquilo que da linguagem ex-siste ao sentido, a saber, o inconsciente enquanto Real. Por isso, a topologia estrutural não insere na teoria uma série de figuras, imagens dos conceitos. Lacan é absolutamente claro quanto a isso: em topologia, não se trata de ver e compreender, mas de manejar os objetos fazendo as abstraçóes necessárias de acordo com as leis desse espaço não intuitivo e alheio ao sentido. Seguimos a citação acima:

Parto da suposiçáo de que, no analista que manipula frequentemente esses artifícios, a familiaridade que chega a adquirir com eles pode habituá-lo pouco a pouco a, senão a perceber, pelo menos a imaginar até um certo ponto um espaço diferente, mais próximo da representação topológica do real psíquico. Não se trataria mais de pretender eliminar a intuiçāo em proveito de um suposto formalismo topológico, mas de transformá-la. Talvez então o exercício da topologia permitisse a abertura do campo de um novo imaginário ligado à experiência do inconsciente (Nasio, 1991, p. 115).

Seria um Imaginário gerado não pela intuição espacial cotidiana, mas pelas leis da espacialidade própria ao inconsciente freudiano, propostas como homólogas às da topologia. Esvaziado de sentido e intuição, o Imaginário ainda é imaginário, porém? Questionamos Nasio nesse ponto; afinal, não se trata de apreender o Real a partir do Imaginário, mas, muito pelo contrário, de através de um sistema de representaçôes puramente Simbólico conseguir esvaziar o Imaginário que preenche de sentidos e por isso mesmo nubla o Real.

Psic. Clin., Rio de Janeiro, vol. 25, N.I, P. I45 - I6I, 2013 


\section{Analogia e homologia}

Esclarecer a função da referência topológica de Lacan é uma tarefa complicada; afinal, o autor não define seus fundamentos epistemológicos antes de começar sua elaboração, sequer cita a bibliografia que usa. Talvez a epistemologia da articulação topologia-psicanálise tenha se desenvolvido ao longo dos seminários, mas nunca de maneira completamente elucidada. Um momento interessante tem lugar ao final de uma lição, quando F. Wahl questiona Lacan (1964/1998d, p. 89): “A topologia, para o senhor, é um método de descoberta ou de exposiçāo?”. A resposta: "É o referenciamento da topologia própria à nossa experiência de analista que pode ser retomada depois na perspectiva metafísica". Sem maiores explicaçóes, Lacan ainda indica na sequência a segunda parte do livro $O$ visivel e o invisivel de Maurice Merleau-Ponty. Ensaiando uma resposta, porém, diríamos que se trata de ambos, mas mais de um método de descoberta do que de exposição. O termo utilizado por Lacan, traduzido por "referenciamento", é o francês repérage, traduzível por "marcação" ou "reconhecimento". Entendemos que Lacan responde que existe um reconhecimento da topologia que é própria à experiência do psicanalista. É o campo do uso, do "fazer com"; logo, método. Encontramos, mais uma vez, nossa questão central: qual relação a topologia estrutural mantém com o seu objeto? Ela o expóe ou o descobre? Sobre isso, Granon-Lafont (1987) escreve:

Amiúde, por exemplo, um conceito se assenta sobre uma definição da banda de Moebius, e depois, servindo-se de outra, transtorna nossa compreensão deste conceito. Deste modo, faz dar às noçóes um salto lógico idêntico ao salto topológico que consiste em ver em um desenho o traçado do oito interior, o aplanamento de uma superfície moebiana ou uma ilusão de perspectiva (Granon-Lafont,1987, p. 40).

O manejo da topologia (cortar, desenhar, colar, etc) pode ser um método de exposição, mas, para Lacan, sua abstração serve principalmente de método de pesquisa, de exploração do Real do psiquismo. Lidar com a topologia das superfícies segundo as convençóes estabelecidas pela mesma é um contato com o próprio Real; não uma teoria sobre o Real, mas seu próprio tecido estrutural. Lacan (1972/2003a, p. 479) nos conduz a conceber que sua "topologia náo é de uma substância que situe além do real aquilo que motiva uma prática. Não é teoria”. A referência topológica não será compreendida, portanto, como metafórica, visto que não serve para significar outra coisa, não é analogia para os conceitos que através dela se expressam, mas homologia. Segundo Lalande 
(1999), na matemática são consideradas homólogas as partes correspondentes de duas figuras correlativas. Em anatomia, homólogos são os órgãos cuja situação em relação ao corpo e origem embriogênica são correspondentes (por exemplo, as duas asas de um pássaro e os membros anteriores de um mamífero). Os órgãos análogos, por sua vez, são aqueles que cumprem a mesma função e possuem a mesma aparência sem, contudo, a mesma origem e as mesmas conexôes.

As superfícies topológicas não serão consideradas como um modelo expositor de conceitos ou como que significando outra coisa, pois este é o campo da analogia. Lacan (1972/2003a, p. 485) define com clareza que "A topologia não foi 'feita para nos guiar' na estrutura. Ela é a estrutura [...]”. A partir disso, concluímos que, se tomamos as figuras topológicas como suportes analógicos da estrutura, rejeita-se a propriedade que justifica o uso lacaniano das mesmas, a saber, a homologia estrutural. Sobre isso, afirma Granon-Lafont (1987, p. 23): "Em última instância, assim como um 'esquema' possui um valor explicativo e até didático, a topologia intervém como fundamento epistemológico dos conhecimentos trazidos por dito esquema".

Em Modelos, esquemas y grafos en la enseñanza de Lacan (1992), Eidelsztein propóe uma significativa diferença entre o uso dos modelos, esquemas e gráficos no que diz respeito ao seu valor de método. No modelo óptico, segundo Lacan (1960/1998b, p. 679), "a analogia irá fundamentar seu valor de uso como modelo". Os esquemas (L, Z, R e I) e o gráfico do desejo, por sua vez, não exatamente da mesma forma, são considerados topológicos, no sentido de que não são exemplos ou figuras dos conceitos, mas as próprias relaçôes sincrônicas que estes mantêm entre si. Trata-se, portanto, de uma homologia.

Se assumimos que a topologia estrutural tem uma relação homológica com seu objeto, o psíquico, teríamos que considerá-lo como um conceito, produto de elaboração teórica, não como algo dado e "natural". Assim, afasta-se o aspecto ontológico e privilegia-se o metodológico. Mesmo assim, dois problemas afiguram-se a partir dessas afirmaçóes: (a) vimos Lacan afirmar, mais acima, que a topologia "não é teoria"; (b) uma vez que Lacan se refere à "perspectiva metafísica" e Nasio, por sua vez, ao "ser do psíquico, o estatuto ontológico do psiquismo", estaria realmente afastado o aspecto ontológico?

Analisemos o seguinte trecho de Lacan (1960/1998b):

[...] uma estrutura como que aparente (que implicaria a crítica daquilo que o caráter descritivo comporta de natural) e uma estrutura que ele pode declarar distante da experiência (já que se trata do "modelo teórico" que

Psic. Clin., Rio De JANEIRo, vol. 25, N.I, P. I 45 - I6I, 2013 
ele reconhece na metapsicologia analítica), essa antinomia desconhece um modo da estrutura que, por ser terceiro, não deve ser excluído, ou seja, os efeitos que a combinatória pura e simples do significante determina na realidade em que se produz. Pois é ou não o estruturalismo aquilo que nos permite situar nossa experiência como o campo em que isso fala? Em caso afirmativo, "a distância da experiência” da estrutura desaparece, já que opera nela não como modelo teórico, mas como a máquina original que nela póe em cena o sujeito (Lacan, 1960/1998b, p. 655).

Nem a estrutura presente no "dado bruto" e aparente, nem a que o modelo teórico apreende através de uma abstração distante da experiência, mas sim uma terceira via, criadora. Se o sujeito da psicanálise é efeito de linguagem, Lacan propóe que sua realidade é produzida pela "combinatória pura e simples do significante”. É uma afirmação ousada, pois tem como consequência que a topologia estrutural não apenas cria um objeto, um problema de pesquisa, um inconsciente abstrato e homólogo à estrutura, mas é a própria "máquina original" que "póe em cena o sujeito". Ora, se o sujeito é aquilo que um significante representa para outro significante - o que o produz e o que o afanisa, respectivamente -, sua lógica deve corresponder à lógica do significante, e esta deve ser estrutural. Isso confere ao sujeito do inconsciente um aspecto ontológico?

Lacan (1964/1998d), caracteriza o inconsciente como "pré-ontológico", "nem ser nem não-ser, mas algo não-realizado". É um momento do seminário no qual o inconsciente é retomado a partir do seu caráter de hiância, ruptura não sujeita a colagem. "O estatuto do inconsciente, que eu lhes indico tão frágil no plano ôntico, é ético" (1964/1998d, p. 37). Entre dois significantes, o sujeito do inconsciente, de caráter intervalar, se mostra pelo $S_{1}$ já no momento em que se evanesce pelo $S_{2}$. "Onticamente, então, o inconsciente é o evasivo - mas conseguimos cercá-lo numa estrutura, uma estrutura temporal, da qual se pode dizer que jamais foi articulada, até agora, como tal" (Lacan, 1964/1998d, p. 36). A referência à topologia seria, então, contraditória com o estatuto ético, não-ontológico, do inconsciente? Faz-se necessário que a estrutura topológica mantenha sempre uma indefinição, ou seja, que nunca se realize numa plenitude. Fechar essa hiância seria rechaçar o inconsciente. Deve haver nessa estrutura, contudo, algo de apreensível:

[...] a linguística, cujo modelo é o jogo combinatório operando em sua espontaneidade, sozinho, de maneira pré-subjetiva - é esta estrutura que dá seu estatuto ao inconsciente. É ela, e cada caso, que nos garante que há sob

Psic. Clin., Rio de Janeiro, vol. 25, N.I, P. I45 - I6I, 2013 
o termo de inconsciente algo de qualificável, de acessível, de objetivável (Lacan, 1964/1998d, p. 26).

Apreendemos, então, dois pontos fundamentais à topologia estrutural: (a) o estatuto do inconsciente é dado pela lógica do significante e, por isso, responde a uma estrutura que, segundo Lacan, exige uma topologia; (b) a estrutura topológica, porém, não garantirá um estatuto ontológico ao sujeito do inconsciente, pois, se o apreendesse objetivamente numa totalidade, a hiância que o caracteriza enquanto tal seria fechada. Isso remete à proposta de Eco (2007, p. 322) de que a "Estrutura é aquilo que ainda não existe", o que está caracterizado por Lacan (1968-1969/2008, p. 198) na oposição entre verdade e saber: "[...] nesse lugar que chamamos de inconsciente, enuncia-se uma verdade que tem a propriedade de nada podermos saber dela". A partir do diálogo com a teoria dos conjuntos, consegue-se reunir a noção de estrutura, enquanto conjunto de significantes (campo do saber), com a de incompletude, enquanto lugar da falta (campo da verdade): "[...] o que se articula de uma configuraçáo de significantes não significa, de maneira alguma, que se possa totalizar a configuração inteira, isto é, o universo assim constituído" (Lacan, 1968-1969/2008, p. 192).

Um trecho particularmente interessante, novamente de Coelho (1967), lança luz, mesmo sem a intenção de fazê-lo, sobre o aforismo lacaniano que diz que $o$ inconsciente é estruturado como uma linguagem e também sobre a situação da topologia estrutural psicanalítica, isto é, a situação de uma estrutura objetivável ainda que não totalizante. Propóe-se, para tanto, que durante sua leitura a palavra "estrutura" seja substituída por "inconsciente":

É esta a situação da estrutura - a estrutura como algo que apenas está presente nos seus efeitos e que inclui entre os seus efeitos a sua própria ausência, a estrutura como algo que póe o sujeito em cena e lhe atribui um papel, sem nunca se tornar visível em plena evidência dessa cena [...] (Coelho, 1967, p. 28).

\section{Questóes finais: estruturas clínicas}

Este artigo remete a várias questóes que o ultrapassam. Uma delas nos parece, contudo, especialmente relevante. Trata-se da concepção de estrutura clínica e expressa uma importante tensão, já presente no debate estruturalista e assim apresentada por Piaget (2003):

Psic. Clin., Rio de Janeiro, vol. 25, N.I, P. I45 - I6I, 2013 
[...] são as totalidades por composição sempre compostas, mas como ou por quem, ou estiveram antes de tudo (e sempre estáo?) em vias de composição? Em outras palavras, comportam as estruturas uma formação ou não conhecem senão uma pré-formação mais ou menos eterna? (Piaget, 2003, p. 11).

As estruturas clínicas (psicose, neurose, perversão...) com as quais a psicanálise trabalha são invençôes para fins de método ou sugerem um aspecto ontológico? Trata-se de uma questão de primeira importância cujo debate implica a noção de diagnóstico na - ou $d a-$ transferência. As estruturas clínicas, a partir de um primeiro ponto de vista, o metodológico, poderiam ser tomadas como uma ferramenta teórica para reconhecer e operar com as diferentes modalidades de transferência, isto é, do sujeito do inconsciente que tem lugar na clínica psicanalítica. Se as tomamos, porém, como modalidades de subjetivação do indivíduo reconhecíveis fora da transferência, seria fortalecida a suposição de um caráter ontológico. Dessa questão surge uma outra, acerca da influência exercida nas estruturas clínicas pelas mudanças culturais. Novamente, encontram-se pelo menos dois caminhos a seguir. O metodológico, que antes inventa as estruturas ao invés de descobri-las, pode considerá-las um sistema independente, formal e constante. Outro caminho, por sua vez, trata de questionar se formas clínicas como melancolia, depressão, toxicomanias e afins (tratadas por muitos autores como questóes próprias da contemporaneidade) seriam o reconhecimento de incidências particulares de uma nova organizaçáo social que exige que o consagrado sistema neurose-psicose-perversão seja superado. Tais formas, porém, são reconhecidas apenas como novos sintomas, até mesmo como sintomas sociais, ou podem ser teorizadas e formalizadas como novas estruturas clínicas? A primeira opção, ao destacar o fenomênico, acabaria por aproximar a clínica psicanalítica do diagnóstico psiquiátrico, abandonando a busca por organizaçóes psíquicas subjacentes - que, conforme vimos, é comum a Freud e a Lacan. A segunda exigiria uma rigorosa e dupla compreensão: do estatuto teórico da noção de estrutura clínica e da maneira com que a psicanálise se insere na contemporaneidade e o que tem a formular sobre as diversas formas de expressão do mal-estar. São questōes atuais e pertinentes para diversos autores que, a partir da psicanálise, pesquisam novas formas clínicas ou de subjetivação. Propomos que a inserção da noção de estrutura na psicanálise, a topologia estrutural de Lacan enquanto método, serve de fio condutor para essa discussão, justamente na medida em que não a resolve ou esgota.

Psic. Clin., Rio De Janeiro, vol. 25, N.I, P. I45 - I6I, 2013 


\section{Referências}

Coelho, E. P. (1967). Introdução a um pensamento cruel: estruturas, estruturalidade e estruturalismos. In: Coelho, E. P. (org.). Estruturalismo: antologia de textos históricos (pp. 1-75). São Paulo: Livraria Martins Fontes.

Darmon, M. (1994). Ensaios sobre a topologia lacaniana. Porto Alegre: Artes Médicas.

Derrida, J. (1967). A estrutura, o signo e o jogo no discurso das ciências humanas. In: Coelho, E. P. (org.). Estruturalismo: antologia de textos históricos (pp. 101-123). São Paulo: Livraria Martins Fontes.

Eco, U. (2007). A estrutura ausente. São Paulo: Perspectiva.

Eidelsztein, A. (1992). Modelos, esquemas y grafos en la enseñanza de Lacan. Buenos Aires: Editorial Manantial.

Eidelsztein, A. (2006). La topología en la clínica psicoanalítica. Buenos Aires: Letra Viva.

Freud, S. (1996). A questâo da análise leiga. Obras Completas, ESB, v. XX. Rio de Janeiro: Imago. (Trabalho original de 1926)

Freud, S. (1996). Novas conferências introdutórias sobre psicanálise. Obras Completas, ESB, v. XXII. (Trabalho original de (1933 [1932]))

Granon-Lafont, J. (1987). La topología básica de Jacques Lacan. Buenos Aires: Ediciones Nueva Visión.

Lacan, J. (1976-1977). Seminário 24: l'insu que sait de l'une bévue s'aile a mourre. Disponível em: <www.gaogoa.free.fr>. Acesso em 02 ago 2011.

Lacan, J. (1998a). De uma questão preliminar a todo tratamento possível da psicose. Escritos. Rio de Janeiro: Jorge Zahar Editor. (Trabalho original de 1957-1958)

Lacan, J. (1998b). Observação sobre o relatório de Daniel Lagache. Escritos. Rio de Janeiro: Jorge Zahar Editor. (Trabalho original de 1960)

Lacan, J. (1998c). O seminário sobre "A carta roubada”. Escritos. Rio de Janeiro: Jorge Zahar Editor. (Trabalho original de 1966)

Lacan, J. (1998d). O seminário, livro 11: os quatro conceitos fundamentais da psicanálise. Rio de Janeiro: Jorge Zahar Editor. (Trabalho original de 1964).

Lacan, J. (1992). O seminário, livro 17: o avesso da psicanálise. Rio de Janeiro: Jorge Zahar Editor. (Trabalho original de 1969-1970)

Lacan, J. (2003a). O aturdito. Outros escritos. Rio de Janeiro: Jorge Zahar Editor. (Trabalho original de 1972)

Lacan, J. (2003b). O seminário, livro 9: a identificação. Recife: Centro de Estudos Freudianos do Recife. (Trabalho original de 1961-1962)

Lacan, J. (2005). O seminário, livro 10: a angústia. Rio de Janeiro: Jorge Zahar Editor. (Trabalho original de 1962-1963)

Psic. Clin., Rio De JANEIRo, vol. 25, N.I, P. I 45 - I6I, 2013 
Lacan, J. (2008). O seminário, livro 16: de um Outro ao outro. Rio de Janeiro: Jorge Zahar Editor. (Trabalho original de 1968-1969)

Lacan, J. (2009). O seminário, livro 18: de um discurso que náo fosse semblante. Rio de Janeiro: Jorge Zahar Editor. (Trabalho original de 1971)

Lalande, A. (1999). Vocabulário técnico e crítico da filosofia. São Paulo: Martins Fontes.

Lévi-Strauss, C. (1952/2008). A noção de estrutura em etnologia. In: Antropologia estrutural (pp. 299-344). São Paulo: Cosac Naify.

Nasio, J. D. (1991). Os olhos de Laura: o conceito de objeto a na teoria de Lacan seguido de uma introdução à topologia psicanalítica. Porto Alegre: Artes Médicas.

Piaget, J. (2003). O estruturalismo. Rio de Janeiro: DIFEL.

Ruiz, C. (1994). La superficie como estructura. In: Topología y Psicoanálisis. Buenos Aires: Escuela Freudiana de Buenos Aires.

Sampaio, J. C. V. (2002). Topologia das superfícies: uma introdução intuitiva. Recuperado em 02 de agosto de 2011, de <http://www2.dm.ufscar.br/ -sampaio/xiiiebt_superficies.PDF>.

Recebido em 08 de novembro de 2012 Aceito para publicação em 15 de janeiro de 2013 